\title{
Tsunami Loading Analysis and Engineering Prevention and Control
}

\author{
Tiecheng Wang ${ }^{1,2}$, Tao Meng ${ }^{1}$ and Hailong Zhao ${ }^{1,2, *}$ \\ ${ }^{1}$ School of Civil Engineering, Tianjin University, Tianjin, 300072, China \\ ${ }^{2}$ Key Laboratory of Coast Civil Structure Safety (Tianjin University), Ministry of Education, Tianjin, 300072 China
}

\begin{abstract}
Tsunami is one of the serious natural disasters in coastal areas. Tsunami waves produce huge horizontal thrust on costal buildings, resulting in a large number of houses collapsed instantaneously, causing serious casualties and economic losses. Based on a reinforced concrete frame structure under different conditions of tsunami effect analysis, this paper clarified the calculation method of tsunami loading and proposed two kinds of the most disadvantageous combination effects of the tsunami loading, namely the combination effect of the advancing water front of a tsunami and the combination effect of the tsunami inundation. It is indicated that the right structure type and the multi-story or highrise buildings should be chosen in the tsunami damage prevention and control measures, and the ability of the key loadbearing members to resist tsunami impact at the bottom of the structure should be strengthened.
\end{abstract}

Keywords: Tsunami disaster, tsunami loading, combination effect, prevention and control measures.

\section{INTRODUCTION}

Tsunami is a Japanese word meaning "harbor" (tsu) and "wave"(nami). The term was created by fishermen who returned to port to find the area surrounding the harbor devastated [1]. Tsunami is usually triggered by the strong undersea earthquakes, but can also be generated by underwater landslides, volcanic eruptions, onshore slope failures that fall into the ocean or even meteor impacts. Tsunami wavelength can reach $10 \sim 100 \mathrm{~km}$, which is even larger than the maximum depth of the ocean. The waves propagating near the seabed do not suffer much block, so the waves can propagate through the ocean thousands of kilometers while the energy attenuates rarely. The velocity decreases while the height increases sharply as the waves approach the shallower waters of the coast. Upon reaching the shoreline the waves carrying huge energy penetrate inland, destroy or roll away all the coastal buildings and people instantly, causing huge loss of life and property [2]. The last decade has been witness to a number of major tsunamis that have resulted in catastrophic human and economic losses to coastal communities (Indian Ocean 2004, Chile 2010, and Japan 2011).

There are a few guidances provided by structural design codes for the forces induced by tsunami effects on coastal construction. A set of generalized equations were created from currently available building codes and published literatures, which contained information and recommended equations on tsunami. The existing design codes investigated are the Federal Emergency Management Agency Coastal Construction Manual (FEMA 55) [3]; the Structural Design Method of Buildings for Tsunami Resistance (SMBTR) [4];

*Address correspondence to this author at School of Civil Engineering, Tianjin University, 300072, P.R. China; Tel: (+86) 13920115670;

E-mail: hlongzhao@126.com the American Society of Civil Engineers Standard ASCE 710 Minimum Design Loads for Buildings and Other Structures [5]; and Guidelines for Design of structures for Vertical Evacuation from Tsunamis(FEMA P646) [1]. One of the most representative, and also the earliest is the City and County of Honolulu Building Code ( $\mathrm{CCH}(2000))$ developed by the Department of Planning and Permitting of Honolulu, Hawaii, US, for districts located in flood and tsunami-risk areas, which provides specific guidance for structural design of buildings subject to tsunami loading [6].

\section{TYPES OF TSUNAMI LOADING}

According to the above codes, Yeh et al. [7], Thusyanthan [8] and Nistor et al. [9] have indicated that the tsunami loadings acting on structures mainly consist of five parts, namely hydrostatic force $F_{h s}$, buoyant force $F_{b}$, hydrodynamic (drag) force $F_{d}$, surge force $F_{s}$, and debris impact force $F_{i}$. All of the tsunami loadings on structure are shown as Fig. (1).

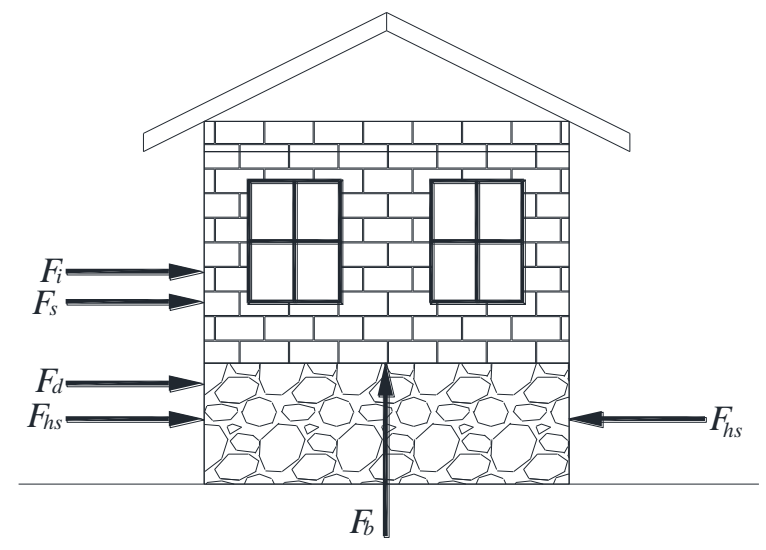

Fig. (1). Tsunami loadings on structure. 
Because the water levels of the wall are different on the front and back surface when the tsunami waves hit housing construction, the hydrostatic force will be generated by the waves acting perpendicular onto wall surfaces. The hydrostatic force per unit width, $F_{h s}$, can be calculated using the equation given below:

$$
F_{h s}=\frac{1}{2} \rho \mathrm{g}\left(h+\frac{u_{p}^{2}}{2 g}\right)^{2}
$$

Where $\rho$ is the seawater density, $g$ is the gravitational acceleration, $h$ is the tsunami wave height, and $u_{p}$ is the normal component of tsunami wave flow velocity. Eq. (1) is adopted by $\mathrm{CCH}$ (2000), hydrostatic force is usually important for long structures such as sea walls and dikes.

When the tsunami waves through the building, the whole building or a single member submerged in water will be affected by the buoyant force, which is the vertical force acting through the center of mass of a submerged body. Its magnitude is equal to the weight of the volume of water displaced by the submerged body. The buoyant force, $F_{b}$, can be calculated using the equation given below:

$F_{b}=\rho \mathrm{g} v$

Where $v$ is the volume of water displaced by the whole building or a single member submerged in water.

Due to the density of the seawater is larger, when the tsunami waves through the building, with a certain speed of the seawater will produce hydrodynamic (drag) force on structures, which is controlled by the maximum value of the product of the inundation depth, the square of flow velocity, and the shape of the structural element. The hydrodynamic (drag) force, $F_{d}$, can be calculated using the equation given below:

$$
F_{d}=\frac{1}{2} \rho C_{d} A u^{2}
$$

Where $C_{d}$ is the drag coefficient for the structural members, for the case of rectangular piles, the drag coefficient recommended by $\mathrm{CCH}(2000)$ is $2.0, A$ is the projected area of the structure normal to the direction of flow velocity, $u$ is the propagation velocity of the tsunami waves.

As the tsunami waves spread from the deep sea to the shore, the surge force is generated by the impingement of the advancing water front of a tsunami bore on a structure. Based on research conducted by Dames and Moore, $\mathrm{CCH}$ (2000) proposes the following expression for the computation of surge force which is proportional to the square of the tsunami wave height. The surge force per unit width, $F_{s}$, can be calculated using the equation given below:

$$
F_{s}=4.5 \rho g h^{2}
$$

Where $h$ is the tsunami wave height, assumed equal to the tsunami wave inundation depth.

A high-speed tsunami wave traveling inland carries debris such as floating automobiles, drift wood, as well as boats and ships. CCH (2000) recommends using Eq. (5) for estimation of the debris impact force, and the debris impact force, $F_{i}$, can be calculated using the equation given below:
$F_{i}=m \frac{u}{\Delta t}$

Where $m$ is the mass of the body impacting the structure, assumed to $455 \mathrm{~kg}$ in $\mathrm{CCH}$ (2000); $u$ is the velocity of the body, assumed equal to the propagation velocity of a tsunami wave; $\Delta t$ is the impact duration.

\section{TSUNAMI LOADINGS COMBINATION EFFECT}

Due to the generated sequences and conditions of tsunami loadings are different, so the phenomenon that the buildings are affected by the five types of tsunami loading at the same time is difficult to appear. This paper, based on the interaction time sequence between the tsunami waves and structures, proposes two tsunami loading combinations analysis, respectively.

When the tsunami waves propagate from sea to shore, what firstly impacts the coastal building is the advancing water front of the tsunami waves in the form of water wall. The forces generated by the impingement of the advancing water front of the tsunami waves on a structure are consist of the surge force $F_{s}$ and debris impact force $F_{i}$. The final tsunami loading on structure, $F_{T}$, can be calculated using the equation given below:

$$
F_{T}=F_{s}+F_{i}
$$

When the tsunami waves cross the building, the building is completely surrounded by water, leading to a relatively stable building inundation condition, the duration of the interaction between water flow and building is stable and long. In this condition, the tsunami loadings are consist of the hydrostatic force $F_{h s}$, buoyant force $F_{b}$, hydrodynamic (drag) force $F_{d}$ and debris impact force $F_{i}$. In this stable inundation condition, the water level surrounding the building will be consistent, so the hydrostatic force will not be used for the evaluation of a building as a whole. Due the $\mathrm{RC}$ structure is arranged with a large number of openings, so the buoyant force on the structure will be small and the adverse effect of the buoyant force will be not considered in engineering design. The final tsunami loading on structure, $F_{T}$, can be calculated using the equation given below:

$F_{T}=F_{d}+F_{i}$

\section{TSUNAMI EFFECT ANALYSIS}

At present, the building designs in some country's coastal areas only consider the effect of the earthquake and structural weight, while the adverse effect of the tsunami loading will be ignored by designers. If the integrity of a building is not strong and structural arrangement is not reasonable enough, hence the ability of the structure to resist tsunami loading will be weak, which will result in a large number of houses damaged even collapsed instantaneously. Supposing one country's coastal areas attacked by tsunami, this paper has calculated the tsunami loadings generated by tsunami waves (inundation) with different depths respectively based on the $\mathrm{CCH}(2000)$, taken a comparative analysis on base shear and tsunami loading, and finally proposed the engineering control and prevention methods for structure to resist tsunami loading. 
In these areas, the seismic fortification intensity is eight degree and the basic earthquake acceleration value is $0.2 \mathrm{~g}$. The structure type is RC frame, and the plan view of the structural layout is showed in Fig. (2). Assuming that the building is impacted by tsunami waves perpendicular to the ongitudinal direction of the building with the wave depths from $1 \mathrm{~m}$ to $16 \mathrm{~m}$. The building with floor height is $3 \mathrm{~m}$, which is designed from four floors to eight floors.

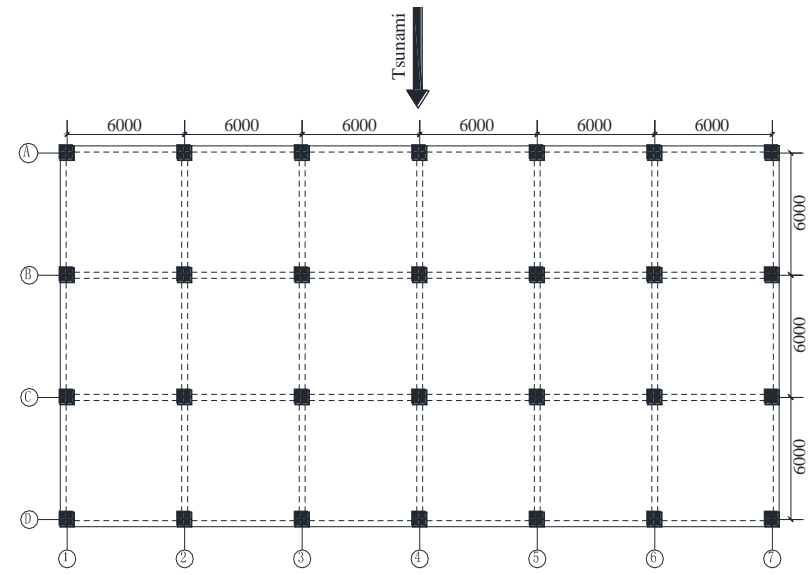

Fig. (2). The plan view of the structural layout.

There are two cases in calculation of the tsunami loadings. Case 1: all filler walls perpendicular to the direction of tsunami waves are destroyed by water and separated completely from the main structure; case 2: all filler walls perpendicular to the direction of tsunami waves are not damaged by water, thus the walls connect completely with the main structure. Using the Eq. (3), Eq. (4) and Eq. (5) can calculate the hydrodynamic (drag) force $F_{d}$, surge force $F_{s}$ and debris impact force $F_{i}$, respectively. Tsunami loadings acting on structures which are generated by different cases and wave (inundation) depths, are shown in Table 1.

It is shown that the hydrodynamic force, surge force and debris impact force display an increasing trend as the tsunami wave height and velocity increase from Table $\mathbf{1}$, especially the hydrodynamic force and surge force increase much fast. In the three types of force, the debris impact force value is the minimum and increasing slowly.

Under case 1 condition, the surge force value is always greater than the hydrodynamic force and debris impact force value as the tsunami wave (inundation) depth is not more than $11 \mathrm{~m}$ and the tsunami loading is predominantly based on the surge force at this time. With the increase of the tsunami wave (inundation) depths from $11 \mathrm{~m}$ to $16 \mathrm{~m}$, the hydrodynamic force value exceeds the surge force value in the same condition and the tsunami loading is predominantly based on the hydrodynamic force at this time. Under case 2 condition, the surge force value is always greater than the hydrodynamic force and debris impact force value, thus the tsunami loading is principally based on the surge force all the time in case 2 .

From Table 1, the tsunami loading combination value, in case 2 , is significantly greater than it under the same

Table 1. The calculated value of tsunami loadings.

\begin{tabular}{|c|c|c|c|c|c|c|c|c|}
\hline $\begin{array}{c}\text { Wave(inundation) } \\
\text { Depths(m) }\end{array}$ & $\begin{array}{l}\text { Velocity* } \\
(\mathbf{m} / \mathbf{s})\end{array}$ & \multicolumn{2}{|c|}{$F_{d}(\mathbf{k N})$} & \multicolumn{2}{|c|}{$F_{s}(\mathbf{k N})$} & $F_{i}(\mathbf{k N})$ & \multicolumn{2}{|c|}{$F_{T}(\mathbf{k N})$} \\
\hline 2 & 2 & 138 & 226 & 764 & 6657 & 9.10 & 773 & 6666 \\
\hline 3 & 3 & 467 & 763 & 1719 & 14978 & 13.65 & 1733 & 14992 \\
\hline 5 & 5 & 2163 & 3534 & 4774 & 42604 & 22.75 & 4797 & 42627 \\
\hline 6 & 6 & 3738 & 6107 & 6875 & 59910 & 27.30 & 6902 & 59937 \\
\hline 7 & 7 & 5935 & 9698 & 9358 & 81545 & 31.85 & 9390 & 81577 \\
\hline 8 & 8 & 8860 & 14476 & 12222 & 106507 & 36.40 & 12258 & 106543 \\
\hline 11 & 11 & 23032 & 37632 & 23108 & 201366 & 50.05 & 23158 & 201416 \\
\hline 12 & 12 & 29901 & 48857 & 27500 & 239642 & 54.60 & 29956 & 239697 \\
\hline 13 & 13 & 38017 & 62117 & 32274 & 281246 & 59.15 & 38076 & 281305 \\
\hline 14 & 14 & 47482 & 77582 & 37430 & 326179 & 63.70 & 47546 & 326243 \\
\hline 15 & 15 & 58401 & 95423 & 42969 & 374440 & 68.25 & 58469 & 374508 \\
\hline 16 & 16 & 70877 & 115808 & 48889 & 426030 & 72.80 & 70950 & 426103 \\
\hline
\end{tabular}

*Velocity: The velocity of tsunami waves is equal to the wave (inundation) depths in CCH (2000). 
conditions in case 1 . The major reason for the results in case 1 is that all filler walls perpendicular to the direction of tsunami waves are destroyed by water and separated completely from the main structure. While in case 2 , all filler walls perpendicular to the direction of tsunami waves are not destroyed and connect completely with the main structure, so the structures, under the wave (inundation) depth, are subjected to wave action and the contact area between waves and structures increases significantly than it in case 1 .

According to the engineering situation, the maximum base shear of the structure with different floors is calculated in sequence by SAP2000. The rates between tsunami loading combination value $F_{T}$ and base shear $F_{V}$, under tsunami wave (inundation) depths from $1 \mathrm{~m}$ to $16 \mathrm{~m}$, are listed in Table 2.

As shown in Table 2, when the tsunami wave (inundation) depth is a constant value under case 1 condition, the rates between $F_{T}$ and $F_{V}$ decrease in accordance with the increase of the number of floors. For example, the rates between $F_{T}$ and $F_{V}$ is not more than 1 and as the numbers of stories for the structure increase from 4 to 8 the rates are $1.000,0.801,0.666,0.609$, and 0.603 in sequence when the tsunami wave (inundation) depth is at $6 \mathrm{~m}$. As same as case 1 condition, when the tsunami wave (inundation) depth is a constant value under case 2 condition, the rates between $F_{T}$ and $F_{V}$ decrease in accordance with the increase of the number of floors. However, when the tsunami wave (inundation) depth is at $3 \mathrm{~m}$, the tsunami loading combination value is greater than the base shear under case 2 , so the case 2 is disadvantageous to resist tsunami for structures.

According to the investigation on the disaster of the East Japan tsunami [2], the structures will be destroyed completely when the rate between tsunami loading combination value $F_{T}$ and base shear $F_{V}$ is close to 3 ; the structures will be destroyed partly when the rate is more than 1 ; and the structures will be in safety state when the rate is less than 1. Based on the results of Table $\mathbf{2}$, it could be found that relationship between structure state in different floor and tsunami wave (inundation) depths, which are displayed in Table 3 .

As the number of stories increases from 4 to 8 under case 1 condition, the results from Table 3 indicate that the highest

Table 2. Rates between tsunami loading combination value $F_{T}$ and base shear $F_{V}$.

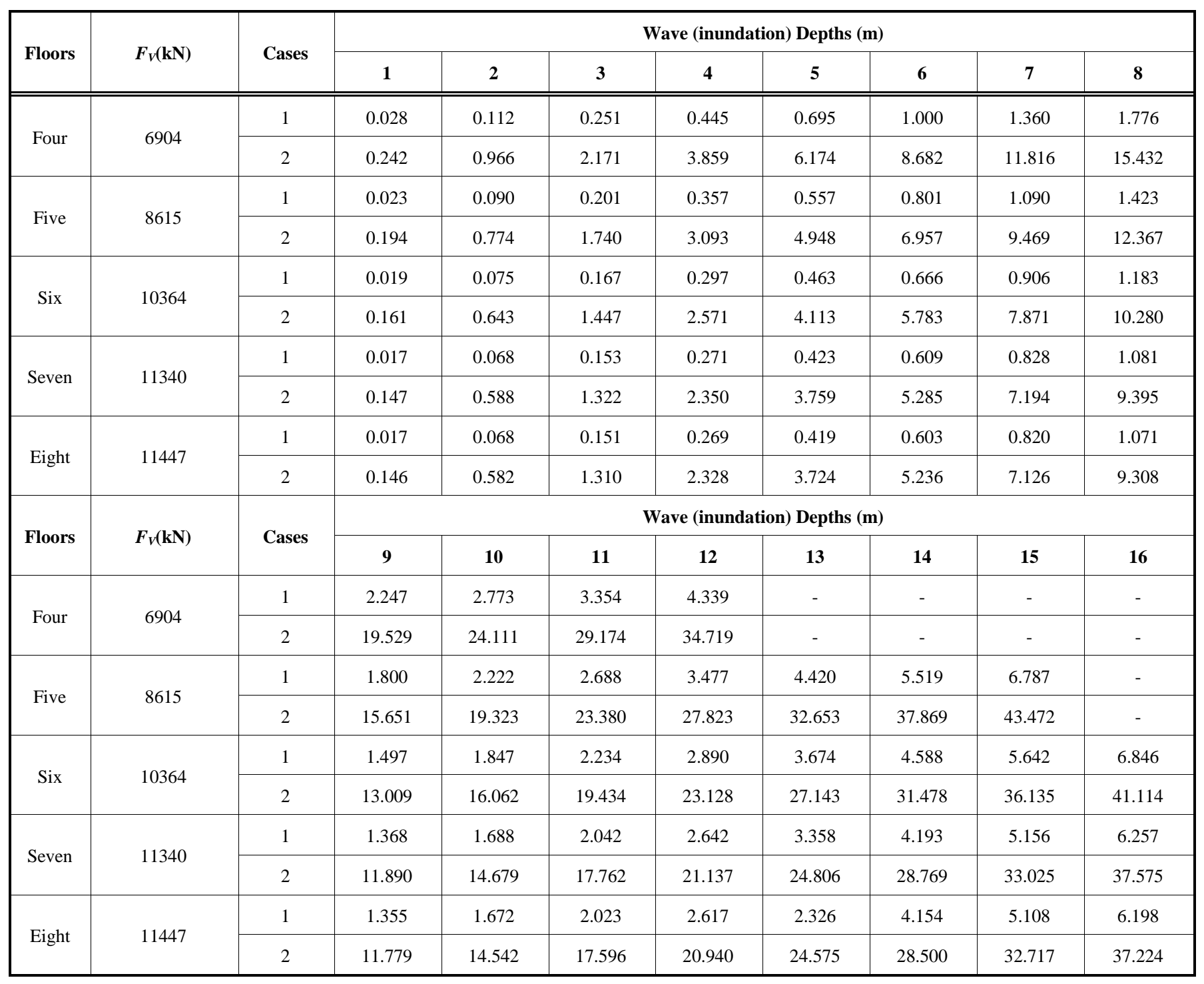


Table 3. Relationship between structure state and tsunami wave (inundation) depths.

\begin{tabular}{|c|c|c|c|c|c|c|c|c|c|c|c|c|c|c|c|}
\hline & \multicolumn{9}{c|}{ Tsunami Wave (inundation) Depths (m) } \\
\hline Structure State & \multicolumn{3}{|c|}{ Safety } & \multicolumn{3}{c|}{ Part Damage } & \multicolumn{3}{c|}{ Total Damage } \\
\hline \hline Floors & 4 & 5 & 6 & 7 & 8 & 4 & 5 & 6 & 7 & 8 & 4 & 5 & 6 & 7 & 8 \\
\hline Case 1 & 6 & 6 & 7 & 7 & 7 & 7 & 7 & 8 & 8 & 8 & 11 & 12 & 13 & 13 & 14 \\
\hline Case 2 & 2 & 2 & 2 & 2 & 2 & 3 & 3 & 3 & 3 & 3 & 4 & 4 & 5 & 5 & 5 \\
\hline
\end{tabular}

tsunami wave (inundation) depth corresponding to safety state on structure is $6 \mathrm{~m}, 6 \mathrm{~m}, 7 \mathrm{~m}, 7 \mathrm{~m}$ and $7 \mathrm{~m}$ respectively, the lowest tsunami wave (inundation) depth corresponding to part damage on structure is $7 \mathrm{~m}, 7 \mathrm{~m}, 8 \mathrm{~m}, 8 \mathrm{~m}$ and $8 \mathrm{~m}$ respectively, and the lowest tsunami wave (inundation) depth corresponding to total damage on structure is $11 \mathrm{~m}, 12 \mathrm{~m}, 13$ $\mathrm{m}, 13 \mathrm{~m}$ and $14 \mathrm{~m}$ respectively. Hence it can be seen that engineers could increase the number of stories to enhance the ability of a structure to resist tsunami and should not build low-rise buildings in tsunami disaster areas.

Under case 2 condition the ability of a structure to resist tsunami is considerably lower than it under case 1 condition, therefore, the tsunami wave in case 2 condition could have the most adverse effect on structures. In engineering design, walls normal to the direction of tsunami waves should not be arranged too much at the bottom of a structure to decrease the tsunami loadings on the main structure and lead to the structure subjected to tsunami waves under case 1 condition. That is, it is better to calculate the tsunami loading under case 1 condition in actual design of a structure to resist the tsunami.

\section{ENGINEERING PREVENTION AND CONTROL METHODS ON TSUNAMI}

According to the aforementioned analysis on tsunami loading on structure, designers could adopt the proper engineering prevention methods to reduce the forces generated by the tsunami waves on structures in tsunami potential disaster areas, and improve the ability of structures to resist tsunami loading.

Considering the structural characteristics of the buildings, the building that is advantageous to resist tsunami loading can be constructed by means of reducing the force applied to the building. Walls normal to the direction of tsunami waves should not be arranged too much at the bottom of a building, and the open system buildings with openings should be designed to allow tsunami waves to flow through with minimal resistance.

When the buildings with different stories are analyzed to support equal tsunami loadings under the same level of the tsunami wave (inundation) depth, the calculation results indicate that the multi-storey or high-rise housings have more strong capacity in resisting the horizontal load at bottom of building than the low-rise housings. Therefore, in tsunami potential disaster areas, engineers can build the multi-storey or high-rise housings to reduce the damage generated by tsunami.

The structural design should be reasonable, and the appropriate engineering design method does not significantly increase the cost of the structure to resist earthquake but can reduce the tsunami damage on structures to a minimum. Besides the general load, the surge force, hydrodynamic (drag) force, debris impact force and their combination effect should be also calculated respectively in design of structure to determine the final tsunami loading. The tsunami loading should be calculated under case 1 condition in actual design of structures to resist tsunami.

Although the debris impact force is relatively small, it may cause some damage to the bearing members, and even lead to progressive collapse of the entire structure when the tsunami waves with floater hit the key load-bearing members at the bottom of the structure. Therefore, it is very important to strengthen the key load-bearing members to resist impact at bottom of the structure.

\section{CONCLUSION}

Tsunami can seldom be accurately predicted due to its own characteristics, and the frequency of tsunami disaster in coastal areas of the world is on increase in recent years, thus improving the ability of buildings to resist tsunami in coastal areas becomes the inevitable choice to reduce casualties and economic losses in that regions. Based on the analysis of the types of tsunami loading acting on the structure as well as their calculation methods, two kinds of the most disadvantageous combination effect of the tsunami loading are proposed in this paper, namely the combination effect of the advancing water front of a tsunami and the combination effect of the tsunami inundation.

The calculations and analyses of the RC frame structure to resist tsunami indicate that the prevention and control measures to reduce tsunami damage should select the proper structure types, which could reduce the tsunami loadings acting on the structures, build multi-story or high-rise buildings to enhance the ability of the structures to resist tsunami loadings, and strengthen the key load-bearing members to resist impact at bottom of the structures.

As results from Table 3 indicate that the ability of the structure, under case 2 condition, to resist tsunami effect is much lower than it under case 1 condition, therefore, the tsunami waves in case 2 condition could have the most disadvantageous effect on structures. In engineering design, buildings should be subjected to tsunami wave action under case 1 condition. That is, it is better to calculate the tsunami loading under case 1 condition in actual design of the structures to resist tsunami. 


\section{CONFLICT OF INTEREST}

The authors confirm that this article content has no conflict of interest.

\section{ACKNOWLEDGEMENTS}

Declared none.

\section{REFERENCES}

FEMA P646. Guidelines for Design of Structures for Vertical Evacuation from Tsunamis. Applied Technology Council, FEMA, Washington, DC, 2012, pp. 7-8.

[2] F.L. Zhou, H.C. Cui, E.A.B. Shigetaka, X.L. Lu, Y. Sun, Z.B. Li, A. Li, D. Feng, Y.M. Li, S.T. Xue, L.J. Bao, "Inspection report of the disaster of the east Japan earthquake by sino-Japanese joint mission", Building Structure, vol. 42, no. 4, pp. 1-20, 2012

[3] FEMA 55, Coastal Construction Manual (4 ${ }^{\text {rd }}$ Edition), FEMA, Washington D.C. 2011, pp. 3-19.
[4] T. Okada, T. Sugano, T. Ishikawa, T. Ohgi, S. Takai, and C. Hamabe, Structural Design Method of Buildings for Tsunami Resistance (SMBTR). The Building Technology Research Institute of The Building Center of Japan, 2005.

[5] ASCE. Minimum Design Loads for Buildings and Other Structures, ASCE/SEI Standard 7-10, American Society of Civil Engineers, Reston, Virginia, USA, 2010.

[6] Department of Planning and Permitting of Honolulu Hawaii. City and County of Honolulu Building Code (CCH 2000), Honolulu, Hawaii, 2000.

[7] H. Yeh, "Design tsunami forces for onshore structures", Journal of Disaster Research, vol. 2. no. 6, pp. 531-536, 2007.

[8] N.I. Thusyanthan, and S.P.G. Madabhushi, "Tsunami wave loading on coastal houses: a model approach," New Civil Engineer International, vol. 161, pp. 77-86, 2008

[9] I. Nistor, D. Palermo, Y. Nouri, T. Murty, and M. Saatcioglu, Tsunami Induced Forces on Structures. Handbook of Coastal and Ocean Engineering, 2008, pp. 261-286.

Received: April, 152015

(C) Wang et al.; Licensee Bentham Open.

This is an open access article licensed under the terms of the Creative Commons Attribution Non-Commercial License (http://creativecommons.org/licenses/ by-nc/3.0/) which permits unrestricted, non-commercial use, distribution and reproduction in any medium, provided the work is properly cited. 